Original Article

\title{
Is the SPARTACUS 15-15 test an accurate proxy for the assessment and tracking of maximal aerobic capacities in adolescents with obesity?
}

\author{
Alicia Fillon $^{1-3)^{*}}$, Maud Miguet ${ }^{1)}$, Grace O’Malley ${ }^{4}$, Marie-Eve Mathied $^{5,6)}$, \\ Julie Masurier $^{3)}$, Valérie Julian $\left.{ }^{2}, 7,8\right)$, Charlotte Cardenoux ${ }^{9}$, Bruno Pereira $^{10)}$, \\ Olivier Rey ${ }^{11)}$, Martine Duclos ${ }^{2}$ 7, 8, 12), Yves Boirie ${ }^{2,8,12,13)}$, David Thivel ${ }^{1,12)}$ \\ 1) Clermont Auvergne University: EA 3533, Laboratory of the Metabolic Adaptations to Exercise \\ under Physiological and Pathological Conditions (AME2P), Clermont-Ferrand, France \\ 2) INRA, France \\ 3) UGECAM Nutrition Obesity Ambulatory Hospital, France \\ 4) School of Physiotherapy, Division of Population Health Sciences, The Royal College of Surgeons in \\ Ireland, Ireland \\ 5) School of Kinesiology, University of Montreal, Canada \\ 6) Sainte-Justine UHC Research Center, Canada \\ 7) Department of Sport Medicine and Functional Explorations, Clermont-Ferrand University Hospital, \\ G. Montpied Hospital, France \\ 8) UFR Medicine, University Clermont Auvergne, France \\ 9) Pediatric Obesity Department, Children Medical Center, France \\ 10) Biostatistics unit (DRCI), Clermont-Ferrand University Hospital, France \\ 11) Aix Marseille University, France \\ 12) CRNH-Auvergne, France \\ 13) Department of Human Nutrition, Clermont-Ferrand University Hospital, G. Montpied Hospital, France
}

\begin{abstract}
Purpose] While there is a need for reliable field tests for the evaluation of physical fitness in pediatric obesity, the present work i) evaluates the validity of the Spartacus 15-15 test in indirectly assessing maximal aerobic capacity in adolescents with obesity and ii) evaluates its sensibility to weight loss. [Participants and Methods] Fiftyfive 11-16 year-old adolescents with obesity (Tanner 3-4) were enrolled in a 12-week weight-management intervention. Maximal Aerobic fitness $\left(\mathrm{VO}_{2 \text { peak }}\right.$ test + Spartacus test) and body composition (Dual X-ray absorptiometry) were assessed at baseline and after 12 weeks. [Results] Moderate correlations were found at baseline between $\mathrm{VO}_{2 \text { peak }}(2,231.90 \pm 465.6 \mathrm{~mL} / \mathrm{min})$ and Spartacus stage $(6.83 \pm 1.8$ stage, $\mathrm{r}=0.52 ; \mathrm{p} \leq 0.05)$, speed $(12.85 \pm 1.8 \mathrm{~km} / \mathrm{h}$, $\mathrm{r}=0.52 ; \mathrm{p} \leq 0.05)$ and time $(20.6 \pm 5.4 \mathrm{~min} ; \mathrm{r}=0.50 ; \mathrm{p} \leq 0.05)$. The intervention favored significant improvements for $\mathrm{VO}_{2 \text { peak }}$, Spartacus Rate of Perceived Exertion final stage, maximal speed and time. Change over time in $\mathrm{VO}_{2 \text { peak }}$ and Spartacus variables were not correlated. [Conclusion] The Spartacus test can be used as a proxy for $\mathrm{VO}_{2 \text { peak }}$ at baseline and can be used to estimate $\mathrm{VO}_{2 \text { peak }}$ using the proposed equation. The Spartacus 15-15 test might be a better indicator for changes in functional capacity than an indicator of $\mathrm{VO}_{2 \text { peak }}$ changes in youth with obesity. Key words: Aerobic fitness, Obese adolescents, Field test
\end{abstract}




\section{INTRODUCTION}

The alarming prevalence of overweight and obesity among children and adolescents is associated with early psychological, metabolic and functional complications ${ }^{1-4)}$. Effective weight management interventions, which employ reliable methods for evaluating health outcomes, are of great importance for the prevention of such co-morbidity and monitoring change over time.

Reliable evaluation methods are particularly necessary for measuring and monitoring change in outcomes related to an individual's physical fitness. While laboratory-based tests are considered as gold standards, access is often limited and testing too costly. This is particularly true when it comes to aerobic fitness where maximal incremental cycling or running tests require direct measurements of oxygen uptake and the supervision of a specialized healthcare staff.

Although indirect, maximal, progressive and continuous field tests are in use, their accuracy remains uncertain, in youth with obesity. Among them, the adapted 20-meter shuttle run test (20-SRT) $)^{5}$ and the continuous multi-stage track test $\left.(\mathrm{MSTT})^{6}\right)$ are often used. Although these provide satisfactory ${ }^{7)}$ and reproducible ${ }^{8)}$ tests among lean children and adolescents, their reliability in youth with obesity is questionable ${ }^{9}$. The MSTT consists of a progressive and continuous test, which oftentimes is prematurely stopped in youth with obesity due to a premature and exacerbated fatigue elicited by the back and forth running. Early stoppage may potentially yield inaccurate estimates of maximal aerobic capacity since youth with obesity often prefer intermittent short-term exercise versus longer continuous exercise regardless of intensity ${ }^{10)}$. Similarly, the 20-SRT is composed of uninterrupted runs requiring sudden changes in direction which generate high energy costs and musculoskeletal pain and discomfort; all of which lead to premature halting of the test in children with obesity ${ }^{11)}$. The impact on musculoskeletal comfort is of particular importance since musculoskeletal and functional limitations are proposed as a main limiting factor during the assessment of aerobic fitness in children and adolescents with overweight and obesity ${ }^{12)}$.

The Spartacus 15-15 field test was developed as an intermittent maximal running field test alternating running and rest periods ${ }^{13)}$. According to Rey and collaborators, a 20\% higher mean maximal speed is observed using the Spartacus compared to the 20-MSTT in adolescents with obesity despite similar maximal heart and perceived exertion rates ${ }^{14)}$. Our research group recently showed that the Spartacus 15-15 test was highly reproducible among adolescents with obesity and that higher $\mathrm{VO}_{2 \text { peak }}$ and $\mathrm{HR}_{\text {peak }}$ were obtained using this test compared with other progressive, continuous and maximal test ${ }^{10)}$. Although the Spartacus test is a reliable method for assessing maximal aerobic capacity among youth with obesity, it has never been compared with a direct laboratory-based measurement of $\mathrm{VO}_{2 \text { peak }}$ and it remains unknown whether results obtained using this test are sensible to weight loss. Indeed, while many studies use the above-mentioned indirect filed tests when questioning the effect of weight loss interventions on the physical fitness of adolescents with obesity, their validity and reliability rest on cross-sectional studies, and we did not find any work that investigate their sensitivity to weight loss compared with direct measures such as $\mathrm{VO}_{2 \max }$.

The first aim of the present study was to test the validity of the Spartacus as an indirect test for assessing maximal aerobic capacities compared with a direct laboratory-based measurement of $\mathrm{VO}_{2 \text { peak }}$ and, secondly, to investigate its sensibility to weight loss in adolescents with obesity. We hypothesize that the Spartacus is a reliable proxy to estimate $\mathrm{VO}_{2 \text { peak }}$ in adolescents with obesity and that this intermittent field test shows a significant sensibility to weight loss in this population.

\section{PARTICIPANTS AND METHODS}

Patients attending a specialized pediatric clinic (Pediatric Obesity Department of Romagnat and Tzanou, La Bourboule, France), were eligible to participate in this study. Patients were eligible if they had a Body Mass Index (BMI) above the 90th percentile according to the international reference values ${ }^{15)}$, were free of any physical contraindications (i.e. recent fracture, articulation issues, etc.) and did not use any medication that could interfere with the principal outcomes of the study. The adolescents and their legal representatives received information sheets and gave their written consent for participation as requested by the ethical authorities (Committee for Human Protection: CPP Sud Est VI, Clinical Trial: NCT02482220).

Following an initial cardiac test and a medical screen by a pediatrician to ensure the ability of the adolescents to complete the protocol, anthropometric measurements were performed, body composition assessed by dual-energy X-ray absorptiometry (DXA, QDR 4500 Hologic), their maximal aerobic fitness $\left(\mathrm{VO}_{2 \text { peak }}\right)$ evaluated and they were asked to perform a Spartacus run test. Participants were then enrolled in a 3-month inpatient multidisciplinary intervention designed to induce weight-loss and all measurements were repeated after 12 weeks (T1).

A digital scale (SECA, les Mureaux, France) was used to measure body mass to the nearest $0.1 \mathrm{~kg}$, and height to the nearest $0.5 \mathrm{~cm}$ (SECA, les Mureaux, France). Body Mass Index (BMI) was calculated as body mass (kg) divided by height squared $\left(\mathrm{m}^{2}\right)$. Waist circumference was measured at the level midway between the last rib and the upper iliac crest. Body composition (Fat Mass percentage (FM\%) and Fat-Free Mass (kg)) was assessed using Dual X-ray absorptiometry (DXA, QDR 4500A scanner, Hologic, Waltham, MA, USA).

Each $\mathrm{VO}_{2 \text { peak }}$ was completed under similar conditions at the same time of the day. $\mathrm{VO}_{2 \text { peak }}$ was measured during a graded exhaustive cycling test ${ }^{16}$ ) that was performed at least one week prior to the Spartacus test, by a specialized medical investigator from the Department of Sports Medicine, Functional and Respiratory Rehabilitation (Clermont-Ferrand University Hospital). The initial power was set at $30 \mathrm{~W}$ for $3 \mathrm{~min}$ and followed by $15 \mathrm{~W}$ increments every $1.5 \mathrm{~min}$. Adolescents were 
strongly encouraged by experimenters throughout the test to perform a maximum effort. Criteria for reaching $\mathrm{VO}_{2 \text { peak }}$ were subjective exhaustion with heart rate above 195 beats $\cdot \mathrm{min}^{-1}$ and/or Respiratory Exchange Ratio (RER, VCO2/VO2) above $1.02 \mathrm{and} /$ or a plateau of $\mathrm{VO}_{2}$. An electromagnetically-braked cycle ergometer (Ergoline, Bitz, Germany) was used to perform the test. $\mathrm{VO}_{2}$ and $\mathrm{VCO}_{2}$ were measured breath-by-breath through a mask connected to $\mathrm{O}_{2}$ and $\mathrm{CO}_{2}$ analyzers $(\mathrm{Oxycon}$ Pro-Delta, Jaeger, Hoechberg, Germany). Calibration of gas analyzers was performed with commercial gases of known concentration. Ventilatory parameters were averaged every $30 \mathrm{~s}$. ECG was monitored for the duration of the test.

Each Spartacus test was completed under similar conditions at the same time of the day. As previously described by Rey et al., a rectangle of 750 meters $(75 \times 10 \mathrm{~m})^{2}$ was created with different marks set at regular intervals, which represent the different speeds (from 7 to $18 \mathrm{~km} / \mathrm{h})^{14}$ ). Each stage lasts three minutes whereby the first stage is set at $7 \mathrm{~km} / \mathrm{h}$ and each following stage increasing by $1 \mathrm{~km} / \mathrm{h}$ every three minutes. During the three minutes (for each stage/ speed), participants had $15 \mathrm{sec}$ to reach the corresponding mark and then $15 \mathrm{sec}$ of rest. As such, each stage lasts three minutes and is composed of $90 \mathrm{sec}$ of running and $90 \mathrm{sec}$ of rest. As soon as the participant was not able to complete a whole stage, the test was interrupted and the last completed stage recorded. Participants ran in groups of no more than 5. Figure 1 illustrates the Spartacus protocol. Heart rate was continuously monitored during the test (Polar Electro Inc. RS800CX) and the adolescents' rate of perceived exertion (RPE) was also evaluated at the end of different stage using an adapted version of the Borg Scale (rated from 0 to 10 with 10 representing a maximal effort that cannot be sustained and the need to interrupt the test).

The fifty-five adolescents were enrolled in a 12-week weight management program combining dietary education and physical activity, at the Pediatric Obesity clinical center (Centre Medical Infantile Romagnat \& Tzanou, France). Every week, adolescents completed two 60-minute exercise sessions combining resistance and aerobic exercises as well as a third session composed of combined recreative activities and sport games (i.e. ball and racquet games or recreational activities such as trekking or snowshoeing). The adolescents also attended nutritional education classes twice a month led by a dietician and received psychological support through individualized consultation with a professional once a month. During the intervention, the adolescents were submitted to a normo-caloric diet based on their age and gender recommendations ${ }^{17}$.

The statistical analyses were carried out using the statistical software Stata (version 13, StataCorp, College Station, USA). All statistical tests were conducted for a two-sided type I error at 0.05 . Continuous variables were described as mean and standard-deviation or median and interquartile range, according to statistical distribution (assumption of normality studied using Shapiro-Wilk test). Paired comparisons were performed using paired Student t-test, or Wilcoxon test when assumptions of t-test were not met. The results were expressed as paired Hedges's effect-sizes. Furthermore, the relationships between quantitative parameters were studied using correlation coefficients (Pearson or Spearman according to the statistical distribution), applying a Sidak's correction to take into account multiple comparisons. Then, to estimate $\mathrm{VO}_{2 \text { peak }}$, an equation has been proposed by multiple linear regression model. The covariates were determined according to univariate results and clinical relevance: age, gender and BMI. The normality of residuals was studied using the Shapiro-Wilk test and a logarithmic transformation of dependent variable was proposed to achieve the normality. A particular attention was paid on study of multicollinearity. The results were expressed as regression coefficients and $95 \%$ confidence intervals.

\section{RESULTS}

The whole sample was aged $13.1 \pm 1.2$ years with a body mass of $92.16 \pm 14.1 \mathrm{~kg}$ and a mean BMI of $35.06 \pm 4.3 \mathrm{~kg} / \mathrm{m}^{2}$. The adolescents mean fat mass percentage and fat free mass were $37.97 \pm 3.9 \%$ and $55.41 \pm 9.0 \mathrm{~kg}$ respectively.

Baseline (T0), $\mathrm{VO}_{2 \text { peak }}(2,231.90 \pm 465.6 \mathrm{~mL} / \mathrm{min})$ was significantly correlated with the $\mathrm{T} 0$ last Spartacus stage $(6.83 \pm 1.8$

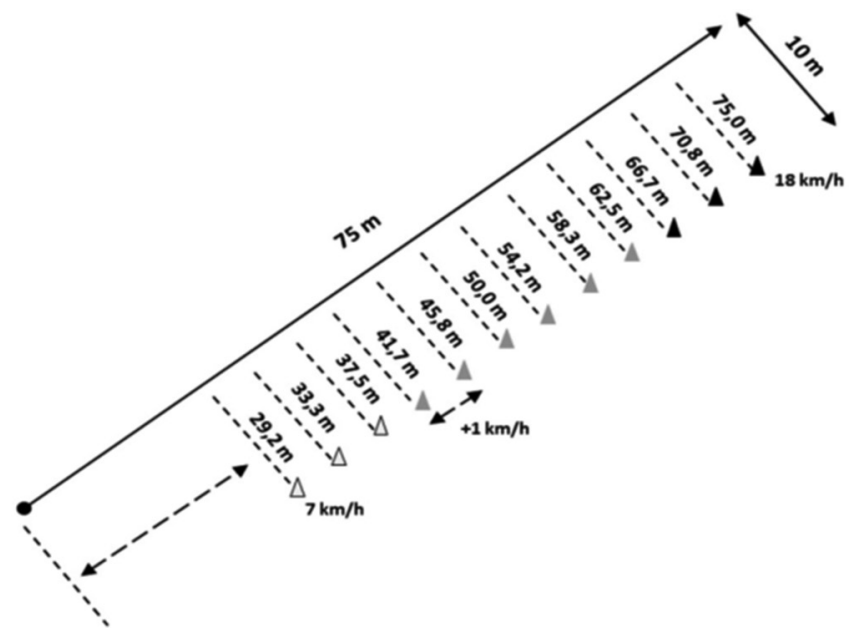

Fig. 1. The Spartacus protocol (adapted from Rey et al., 2013) 
stage; $\mathrm{r}=0.52 ; \mathrm{p} \leq 0.05)$; distance $(53.28 \pm 7.4 \mathrm{~m} ; \mathrm{r}=0.52 ; \mathrm{p} \leq 0.05)$, speed $(12.85 \pm 1.8 \mathrm{~km} / \mathrm{h} ; \mathrm{r}=0.52 ; \mathrm{p} \leq 0.05)$ and time $(20.6 \pm$ $5.4 \mathrm{~min} ; \mathrm{r}=0.50 ; \mathrm{p} \leq 0.05)$.

An equation can be proposed to estimate $\mathrm{VO}_{2 \text { peak }}$ based on the performance obtained during the Spartacus test (Table 1 details the results of the multivariate regression performed to compute this equation). This equation integrates "age", "gender", "BMI" and "last SPARTACUS stage validated" (r=0.68):

$\mathrm{VO} 2_{\text {peak }}$ estimation equations:

Girl: Last stage * $153.4433+$ BMI * 58.64534 + age * -2.701522-921.2878

Boy: Last stage * $153.4433+320.1583+$ BMI $* 58.64534+$ age $*-2.701522-921.2878$

As described by Table 2, body mass was significantly decreased (ES: $0.38[-0.2-0.96] ; p \leq 0.001$ ), as well as BMI (ES: 0.7 [0.11-1.3]; $\mathrm{p} \leq 0.001$ ) and fat mass (ES: 0.97 [0.36 - 1.58]; $\mathrm{p} \leq 0.001$ ), while fat free mass did not change significantly.

Table 3 presents the $\mathrm{VO}_{2 \text { peak }}$ and Spartacus test results between baseline and $\mathrm{T} 1 . \mathrm{VO}_{2 \text { peak }}$ was significantly improved by the end of the intervention (ES: $-0.43[-1.01-0.16] ; p<0.05$ ). The Spartacus RPE (ES: $-2.29[-0.89-0.31] ; p \leq 0.05$ ), last completed stage $(-0.84[-1.45$ to -0.23$] ; \mathrm{p} \leq 0.001)$, maximal speed $(-0.81[-0.41$ to -0.21$])$, total times $(-0.79$ [ -1.39 to

Table 1. Results from the multivariate regression used for the elaboration of the equation

\begin{tabular}{lcccc}
\hline & Coefficient & SD & $95 \% \mathrm{CI}$ & $\mathrm{p}$ \\
\hline Last stage & 153.4 & 30.7 & {$[91.4,215.4]$} & $* * *$ \\
BMI $\left(\mathrm{kg} / \mathrm{m}^{2}\right)$ & 58.6 & 13.3 & {$[31.6,85.6]$} & $* * *$ \\
Age $($ years $)$ & -2.7 & 46.8 & {$[-97.1,91.7]$} & 0.954 \\
Gender $^{\mathrm{a}}$ & 320.1 & 97.1 & {$[124.2,516.0]$} & $* * *$ \\
Constant variable & -921.2 & 600.4 & {$[-2131.3,288.7]$} & 0.132 \\
\hline
\end{tabular}

SD: Standard Deviation; CI: Confidence Interval; $* * * p<0.001 ;{ }^{a}$ when gender is boy.

Table 2. Body composition and comparison between $\mathrm{T} 0$ and $\mathrm{T} 1$

\begin{tabular}{lcccc}
\hline & T0 & T1 & ES & $\mathrm{p}$ \\
\hline Body mass $(\mathrm{kg})$ & $92.16 \pm 14.1$ & $85.0 \pm 15.7$ & $0.38[-0.2,0.96]$ & $* * *$ \\
BMI $\left(\mathrm{kg} / \mathrm{m}^{2}\right)$ & $35.06 \pm 4.3$ & $32.1 \pm 4.3$ & $0.7[0.11,1.3]$ & $* * *$ \\
Fat mass $(\%)$ & $37.97 \pm 3.9$ & $32.1 \pm 4.3$ & $0.97[0.36,1.58]$ & $* * *$ \\
Fat free mass $(\mathrm{kg})$ & $55.41 \pm 9.0$ & $54.3 \pm 10.0$ & $-0.006[0.56,0.57]$ & \\
\hline
\end{tabular}

T0: baseline; T1: end of the intervention; BMI: Body Mass index; ES: Effect Size; ${ }^{*} \mathrm{p}<0.05 ;{ }^{* *} \mathrm{p}<0.01$.

Table 3. Results and comparison between $\mathrm{T} 0$ and $\mathrm{T} 1$ for the $\mathrm{VO}_{2 \text { peak }}$ and Spartacus test

\begin{tabular}{lcccc}
\hline & $\mathrm{T} 0$ & $\mathrm{~T} 1$ & $\mathrm{ES}[95 \% \mathrm{CI}]$ & $\mathrm{p}$ \\
\hline Laboratory test & & & & $*$ \\
$\mathrm{VO}_{\text {peak }}(\mathrm{ml} / \mathrm{min})$ & $2,231.9 \pm 465.6$ & $2,457.0 \pm 396.2$ & $-0.43[-1.01,0.16]$ & \\
$\mathrm{HR}_{\text {peak }}(\mathrm{bpm})$ & $185.3 \pm 8.5$ & $183.5 \pm 15.3$ & $0.25[-0.32,0.82]$ & \\
Spartacus 15-15 test & & & & $*$ \\
$\mathrm{RPE}_{\text {end }}(\mathrm{scale} 1-10)$ & $8.1 \pm 1.7$ & $6.4 \pm 2.4$ & $-2.29[-0.89,0.31]$ & \\
$\mathrm{HR}_{\text {peak }}(\mathrm{bpm})$ & $193.8 \pm 9.5$ & $191.1 \pm 10.2$ & & $* * *$ \\
Last stage & $6.8 \pm 1.8$ & $8.0 \pm 2.6$ & $-0.84[-1.45,-0.23]$ & $* *$ \\
Maximal distance (m) & $53.3 \pm 7.4$ & $57.7 \pm 11.6$ & $-0.74[-0.12,1.35]$ & $* * *$ \\
Maximal speed (km/h) & $12.9 \pm 1.8$ & $14.1 \pm 2.5$ & $-0.81[-0.41,-0.21]$ & $* * *$ \\
Total time (min) & $20.6 \pm 5.4$ & $24.2 \pm 7.5$ & $-0.79[-1.39,-1.19]$ & $* * *$ \\
RPE last stage T0 & $8.2 \pm 1.6$ & $3.8 \pm 2.1$ & $0.88[0.30,1.45]$ & $* * *$ \\
HR last stage T0 & $176.4 \pm 12.5$ & $186.4 \pm 36.2$ & $-1.67[-0.73,0.39]$ & $*$. \\
\hline
\end{tabular}

T0: baseline; T1: end of the intervention; HR: Heart Rate; RPE: Rate of Perceived Exertion; ES: Effect Size; ${ }^{*}<0.05$; $* * \mathrm{p}<0.01 ; * * * \mathrm{p}<0.001$. 


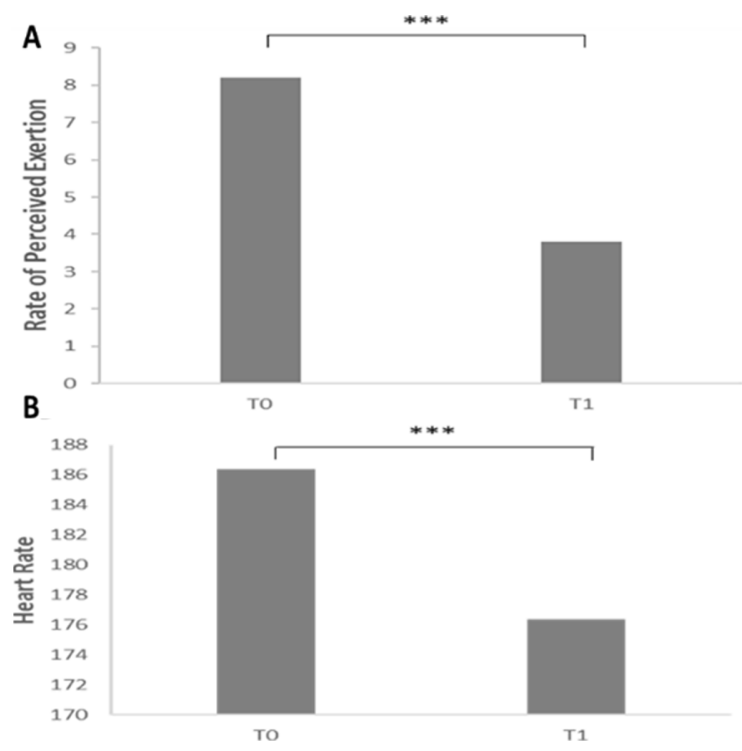

Fig. 2. Changes of the adolescents Rate of Perceived Exertion (A) and Peak of Heart Rate (B) recorded at the end of the last stage completed in the Spartacus test.

T0: baseline; T1: end of the intervention; ${ }^{* * *} \mathrm{p}<0.001$.

$-1.19])(\mathrm{p} \leq 0.001)$ and maximal distance $(-0.74$ [1.35 to -0.12$] ; \mathrm{p} \leq 0.01)$ were significantly improved. Maximal heart rate did not change between baseline and $\mathrm{T} 1$ during both the $\mathrm{VO}_{2 \text { peak }}$ and Spartacus tests.

After the intervention (T1), the adolescents' heart rate and rate of perceived exertion (RPE) recorded at the end of the last stage completed at T0 were both significantly improved $(\mathrm{p}<0.001)$ as illustrated by Fig. 2.

There was no significant correlation between the absolute $\mathrm{VO}_{2 \text { peak }}$ and the Spartacus results at $\mathrm{T} 1$ and the $\mathrm{VO}_{2 \text { peak }}$ and Spartacus results variations (using deltas) were not correlated. None of the Spartacus outcome changes between T0 and T1 was correlated with body weight, BMI, fat mass $\%$ and fat free mass changes. The $\mathrm{VO}_{2 \text { peak }}$ variation was not correlated with body weight and FM $\%$ changes but significantly correlated with fat free mass $(r=0.48 ; p<0.05)$ and $B M I(r=0.49 ; p<0.05)$ variations.

\section{DISCUSSION}

While it exists many field tests to evaluate aerobic fitness among children and adolescents, their accuracy in youth with overweight or obesity remains debated. The first aim of the present work was to test the validity of the Spartacus as an indirect test assessing maximal aerobic capacities compared with a direct measurement of $\mathrm{VO}_{2 \text { peak }}$ and, secondarily, to investigate its sensibility to weight loss in adolescents with obesity.

The Spartacus test, as an intermittent progressive and maximal 15-15 test elaborated to indirectly evaluate children and adolescents' aerobic capacities has been previously compared with usually used field tests such as the 20-MSRT or the Leger-Boucher continuous test and has been found to provide satisfactory results in both lean adolescents and youth with obesity ${ }^{14}, 18$. More recently, Thivel and collaborators suggested that this Spartacus 15-15 test could be more appropriate than the other classically used continuous and progressive field ones for assessing functional capacities in adolescents with obesity ${ }^{19)}$. Although the authors also found the Spartacus 15-15 test to be highly reproducible, they pointed out the need for direct comparisons with laboratory based $\mathrm{VO}_{2 \text { peak }}$ measurements ${ }^{19}$. The present work is to our knowledge the first to directly compare the Spartacus performances to a direct laboratory-based measure of maximal aerobic fitness in adolescents with obesity. According to our results, the Spartacus test provides an accurate estimation of $\mathrm{VO}_{2 \text { peak }}$ in 11 to 16 years old adolescents with obesity. Indeed, our analyses show significant correlations between the different Spartacus outcomes (distance, speed, final stage) and the measured $\mathrm{VO}_{2 \text { peak }}$. Importantly, although these correlations are significant and clinically relevant, they remain moderate, suggesting that the Spartacus test might not be an exact direct proxy for $\mathrm{VO}_{2 \text { peak }}$ but, as previously suggested, might provide a great estimation of the adolescents' aerobic and functional capacities ${ }^{19}$. This is renforced by the fact that these significant correlations have been obtained at baseline only (despite improvement of both $\mathrm{VO}_{2 \text { peak }}$ and Spartacus performances as discussed below). Based on these results, we also propose here the use of an equation integrating the adolescents' individual characteristics (age, gender, BMI) and Spartacus performances (last completed stage) to better estimate baseline $\mathrm{VO}_{2 \text { peak }}$ based on the results obtained during the field test. Since laboratory-based evaluations are rarely available to practitioners and clinicians who rely on indirect field test to assess their patients' capacities ${ }^{20)}$ and based on the 
practical feasibility of the Spartacus test, such an equation can help these practitioners elaborating and calibrating their interventions (individualizing the exercise intensities and their progression for instance). Although some previously published studies proposed equations based on individual characteristics such as body weight and body composition, anthropometric measurements, gender or age to estimate $\mathrm{VO}_{2 \text { peak }}$ among children and adolescents ${ }^{21-23)}$ we found only few studies that proposed an equation integrating performances issued from a field test ${ }^{5,23,24)}$.

Although these first results point out a moderate correlation between the performances obtained during the Spartacus test and a direct measure of $\mathrm{VO}_{2 \text { peak }}$ in adolescents with obesity, we also questioned here whether this field test was sensible to weight loss and whether the improvements observed in response to a multidisciplinary intervention were associated with anthropometric, body composition and $\mathrm{VO}_{2 \text { peak }}$ changes. Our results show significant correlations between the variations of weight, BMI, fat mass (\%) and the improvement of the performances obtained by the adolescents by the end of the intervention, which joins up with previously published studies in the field ${ }^{24}$. However, while both the direct measure of $\mathrm{VO}_{2 \text { peak }}$ and the Spartacus performances (last completed stage, maximal covered distance, HRmax, maximal speed, RPEend and total duration) showed significant improvements in response to a 3-month intervention; we missed to find any correlation between these changes. Indeed, based on our statistical analysis, the moderate correlations observed between $\mathrm{VO}_{2 \text { peak }}$ and the Spartacus performances at baseline did not exist anymore at $\mathrm{T} 1$, and the progression deltas for $\mathrm{VO}_{2 \text { peak }}$ and the Spartacus results were not found correlated. Importantly, our concordance analysis also missed to reveal any relationship between these two tests between $\mathrm{T} 0$ and $\mathrm{T} 1$. Although many studies have used field tests to assess aerobic fitness and its response to weight loss programs in children and adolescents with obesity ${ }^{25,26}$ we missed to find any already existing analysis of the sensitivity of these tests as potential proxies for $\mathrm{VO}_{2}$ changes after weight loss in youth with obesity. This sounds of particular importance since most of researchers and practitioners commonly associate these results as indirect measures for aerobic capacities. Even though the Spartacus (certainly such as other equivalent field tests whose sensibility to weight loss remains to be determined) might not be a great indirect tool to estimate $\mathrm{VO}_{2 \text { peak }}$ changes, our results clearly show significant improvements of its performances in our sample, highlighting its feasibility and potential reliability to assess the adolescents' functional progression after such a multidisciplinary program. These improvements are illustrated by the significant progression of all the results obtained thanks to the Spartacus test at T1 compare with baseline and also interestingly by the significantly lower rate of perceived exertion obtained at $\mathrm{T} 1$ after the completion of the final stage completed at baseline.

The present results have to be considered in light of some limitations. Indeed, the number of participants is rather low, with an unequal girl/boy distribution. Moreover, our panel of participants included pre and post-puberty adolescents aged of 11 to 16 years, which could have influenced the responses to both tests due to the metabolic changes occurring during puberty that influence aerobic capacities ${ }^{27)}$. Mainly, this work lacks from a direct evaluation of the adolescents oxygen consumption during the Spartacus test. Indeed, the use of a portable calorimeter to assess $\mathrm{VO}_{2}$ would have provided important results to enrich our comparison with the laboratory measurement of $\mathrm{VO}_{2 \text { peak. }}$. However, this remained difficult here for practical reasons.

While field tests are mainly used by practitioners, the Spartacus progressive and intermittent maximal 15-15 test proposes a great alternative to laboratory-based evaluation that remains hardly accessible. The present preliminary results add to the actual literature that this Spartacus can be used as an interesting proxy for $\mathrm{VO}_{2 \text { peak }}$ at baseline and proposes an equation based on its performances to estimate $\mathrm{VO}_{2 \text { peak }}$ in adolescents with obesity. Such equations are of particular importance since few practitioners have access to direct measurements of aerobic capacities (such as $\mathrm{VO}_{2 \text { peak }}$ ) that are needed to better calibrate their interventions. It seems however that the improvements observed during a Spartacus test in response to a 3-month multidisciplinary weight loss program cannot be used as proxies for $\mathrm{VO}_{2 \text { peak }}$ changes in this population but as potential indicators of the adolescents' overall functional capacity improvements.

\section{Conflict of interest}

The authors report no conflicts of interest.

\section{ACKNOWLEDGEMENT}

The authors want to thank the adolescents who took part in the study and the UGECAM Nutrition Obesity (Tzanou and the ambulatory clinics) Center for its partnership.

\section{REFERENCES}

1) Ciangura C, Poitou-Bernert C: Complications des obésités. B Endocrinol-Nutr, 2010.

2) Faucher P, Poitou C: [Physiopathology, causes and complications of obesity]. Soins, 2016, 61: 20-25 (in French). [Medline] [CrossRef]

3) Maggio AB, Martin XE, Saunders Gasser C, et al.: Medical and non-medical complications among children and adolescents with excessive body weight. BMC Pediatr, 2014, 14: 232. [Medline] [CrossRef]

4) Tsiros MD, Olds T, Buckley JD, et al.: Health-related quality of life in obese children and adolescents. Int J Obes, 2009, 33: 387-400. [Medline] [CrossRef]

5) Quinart S, Mougin F, Simon-Rigaud ML, et al.: Evaluation of cardiorespiratory fitness using three field tests in obese adolescents: validity, sensitivity and 
prediction of peak VO2. J Sci Med Sport, 2014, 17: 521-525. [Medline] [CrossRef]

6) Léger L, Boucher R: An indirect continuous running multistage field test: the Université de Montréal track test. Can J Appl Sport Sci, 1980, 5: 77-84. [Medline]

7) Tomkinson GR, Léger LA, Olds TS, et al.: Secular trends in the performance of children and adolescents (1980-2000): an analysis of 55 studies of the 20m shuttle run test in 11 countries. Sports Med, 2003, 33: 285-300. [Medline] [CrossRef]

8) Moran CA, Peccin MS, Bombig MT, et al.: Performance and reproducibility on shuttle run test between obese and non-obese children: a cross-sectional study. BMC Pediatr, 2017, 17: 68. [Medline] [CrossRef]

9) Thivel D, Malina RM, Isacco L, et al.: Metabolic syndrome in obese children and adolescents: dichotomous or continuous? Metab Syndr Relat Disord, 2009, 7: 549-555. [Medline] [CrossRef]

10) Thivel D, Isacco L, O’Malley G, et al.: Pediatric obesity and perceived exertion: difference between weight-bearing and non-weight-bearing exercises performed at different intensities. J Sports Sci, 2016, 34: 389-394. [Medline] [CrossRef]

11) Physical activity and obesity: biomechanical and physiological key concepts. https://www.hindawi.com/journals/jobe/2011/650230/ (Accessed Apr. 23, 2018)

12) Ratel S, Duché P, Williams CA: Muscle fatigue during high-intensity exercise in children. Sports Med, 2006, 36: 1031-1065. [Medline] [CrossRef]

13) Rossi D, Mauffrey D, Nicol C: Présentation d'un protocole intermittent de test d'aptitude à l'effort aérobie. Revue Hyper, $2009,4-9$.

14) Rey $\mathrm{O}$, Rossi $\mathrm{D}$, Nicol C, et al.: Évaluation indirecte de la capacité aérobie d'adolescents obèses : intérêt d'un test de course à pied intermittent court, progressif et maximal. Sci Sports, 2013, 28: e133-e139. [CrossRef]

15) Cole TJ, Bellizzi MC, Flegal KM, et al.: Establishing a standard definition for child overweight and obesity worldwide: international survey. BMJ, 2000, 320: 1240-1243. [Medline] [CrossRef]

16) Rowland TW: Does peak VO2 reflect VO2max in children?: evidence from supramaximal testing. Med Sci Sports Exerc, 1993, 25: 689-693. [Medline] [CrossRef]

17) Murphy SP, Poos MI: Dietary reference intakes: summary of applications in dietary assessment. Public Health Nutr, 2002, 5: 843-849. [Medline] [CrossRef]

18) Rey O, Maïano C, Nicol C, et al.: Psycho-physiological responses of obese adolescents to an intermittent run test compared with a 20-M shuttle run. J Sports Sci Med, 2016, 15: 451-459. [Medline]

19) Thivel D, O’Malley G, Blourdier D, et al.: Reproducibility of the intermittent Spartacus Run Test in obese adolescents. J Sports Med Phys Fitness, 2017, 57: 1083-1088. [Medline]

20) O’Malley G, Thivel D: Physical activity and play in children who are obese. M.L. Frelut.

21) Saint-Maurice PF, Welk GJ, Finn KJ, et al.: Cross-validation of a PACER prediction equation for assessing aerobic capacity in Hungarian youth. Res Q Exerc Sport, 2015, 86: S66-S73. [Medline] [CrossRef]

22) Chatterjee P, Banerjee AK, Das P: A prediction equation to estimate the maximum oxygen uptake of school-age girls from kolkata, India. Malays J Med Sci, 2011, 18: 25-29. [Medline]

23) McMurray RG, Guion WK, Ainsworth BE, et al.: Predicting aerobic power in children. A comparison of two methods. J Sports Med Phys Fitness, 1998, 38: 227-233. [Medline]

24) Racil G, Ben Ounis O, Hammouda O, et al.: Effects of high vs. moderate exercise intensity during interval training on lipids and adiponectin levels in obese young females. Eur J Appl Physiol, 2013, 113: 2531-2540. [Medline] [CrossRef]

25) Tjønna AE, Stølen TO, Bye A, et al.: Aerobic interval training reduces cardiovascular risk factors more than a multitreatment approach in overweight adolescents. Clin Sci (Lond), 2009, 116: 317-326. [Medline] [CrossRef]

26) Elloumi M, Makni E, Ounis OB, et al.: Six-minute walking test and the assessment of cardiorespiratory responses during weight-loss programmes in obese children. Physiother Res Int, 2011, 16: 32-42. [Medline] [CrossRef]

27) Ratel S, Blazevich AJ: Are prepubertal children metabolically comparable to well-trained adult endurance athletes? Sports Med, 2017, 47: 1477-1485. [Medline] [CrossRef] 